\title{
Familial Idiopathic Short Stature
}

National Cancer Institute

\section{Source}

National Cancer Institute. Familial Idiopathic Short Stature. NCI Thesaurus. Code C118688.

Idiopathic short stature in a child when either one or both parents is short in stature. 